\title{
IR thermography and heat treatment of metals
}

by SVAIC S. and SUNDOV I. *

*Faculty of Mechanical Engineering and Naval Architecture, University of Zagreb, Croatia

\begin{abstract}
In quenching the essential point is the knowledge of the temperature distribution in the body during the quenching period. In the work the mathematical model for determination of the temperature distribution and calculation of the heat transfer coefficient is given when the probe surface temperature versus time is known. The goal of the project was to find if thermography could be a successful tool in such a case for the surface temperature measurement.
\end{abstract}

$\begin{array}{ll}\text { Nomenclature } & \text { Greek symbols } \\ c \text { specific heat } & \alpha \text { heat transfer coefficient } \\ r \text { radial direction } & \lambda \text { conductivity } \\ t \text { time } & \rho \text { mass density } \\ w \text { air stream velocity } & \varphi \text { angle direction } \\ z \text { axial direction } & \vartheta \text { temperature }\end{array}$

\section{Introduction}

In many engineering problems bodies must be heated and cooled. Very important among them is the heat treatment of metals. This paper deals with the cooling of a metal cylinder inserted into the air stream of the arbitrary chosen temperature and velocity. In reality such a cooling takes place with changeable heat transfer coefficient. During the cooling, temperature field inside the body depends on the changes of the probe surface temperature. The problem has been solved mathematically by obsenving a cylinder with a uniform distribution of the temperature at the beginning of the cooling. The surface temperature during the cooling period was measured by a thermovision camera in steps and the results obtained were used as the input parameters for the mathematical model. The solution of the temperature distribution inside probe, as a function of time and position can be obtained analytically, numerically or graphically. In the work the mathematical model based on the control volume numerical method has been used. The temperature distribution on the cylinder surface has been analyzed to find the influence of the cylinder real dimensions. The control thermocouples were placed in the center of the probe and on their surface as well as $2 \mathrm{~mm}$ below the surface.

\section{The probe, experimental rig and measurement}

The geometry of the probe is given in fig 1. together with the position of the thermocouples. The material of the probe is steel having the heat conduction coefficient $\lambda=49 \mathrm{~W} / \mathrm{mK}$, heat capacity $c=500 \mathrm{~J} / \mathrm{kgK}$ and specific weight of $\rho=7840 \mathrm{~kg} / \mathrm{m}^{3}$. The experimental rig is shown on fig. 2 . The probe was, after being heated, inserted into air stream vertically. The temperatures in the center of the probe, its surface and at the point $2 \mathrm{~mm}$ below the surface were measured during the whole period of cooling and the surface temperature distribution taken in steps by means of the thermographic system. The average surface temperature versus time obtained by thermography has been used as an input parameter for the mathematical model. 
http://dx.doi.org/10.21611/qirt.1994.016

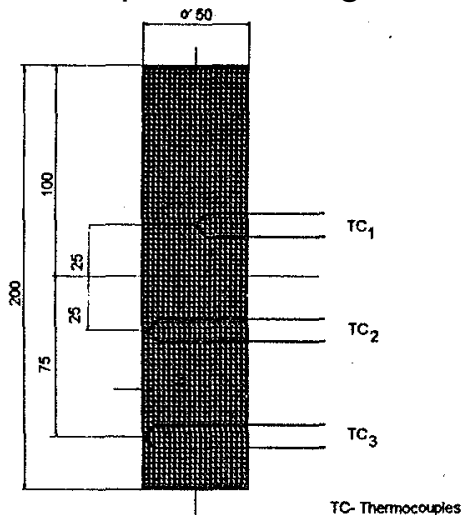

Fig. 1. - Probe with thermocouple position
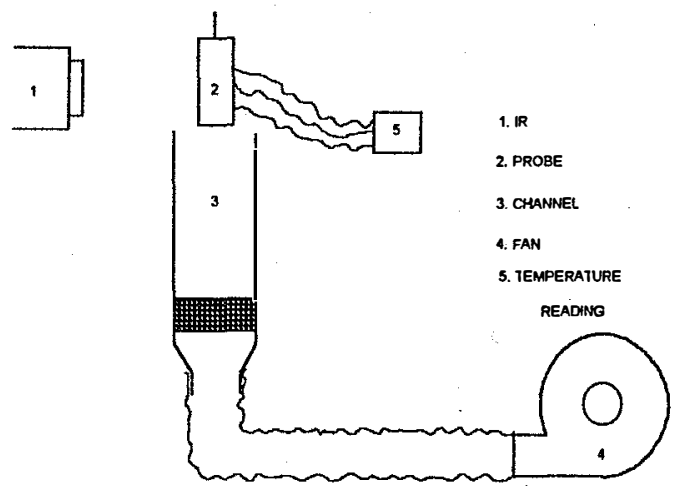

Fig. 2. - Experimental rig

\section{Mathematical model}

The cooling of a cylinder is an unsteady problem where temperature of the body in the observed period is a function of time.

$$
=f(r, \varphi, z, t)
$$

The following assumption was introduced:

- There is no temperature difference in " $\varphi$ " direction

Equation (1) can be written in differential form as:

$$
r c \frac{\partial}{a}=\frac{1}{r} \frac{\partial}{\partial}\left[r \mid \frac{\partial}{\partial}\right]
$$

with the initial condition

$$
t=0 \rightarrow \vartheta(r, z, t=0)=f(r, z)
$$

and the boundary condition

$$
\begin{aligned}
& r=0 \rightarrow \frac{\partial \vartheta}{\partial r}=0 \\
& r=R \rightarrow \vartheta=f(z, t)
\end{aligned}
$$

Numerically problem was solved as the two dimensional one. From eq. (2) the discretization equation for point $P$ gives

$$
\begin{aligned}
& a_{P} \vartheta_{P}=a_{N} \vartheta_{N}+a_{S} \vartheta_{S}+a_{T} \vartheta_{T}+a_{B} \vartheta_{B}+b \\
& a_{N}=\frac{\lambda r_{n} \Delta \varphi \Delta z}{\Delta r} ; \quad a_{s}=\frac{\lambda r_{s} \Delta \varphi \Delta z}{\Delta r} ; \quad a_{T}=a_{B}=\frac{\lambda\left(r_{n}^{2}-r_{s}^{2}\right) \Delta \varphi}{2 \Delta z} \\
& a_{P}^{0}=\frac{\rho c \Delta V}{\Delta t} ; \quad b=a_{P}^{0} \vartheta_{P}^{0} ; \quad a_{P}=a_{N}+a_{s}+a_{T}+a_{B}+a_{P}^{0}
\end{aligned}
$$


http://dx.doi.org/10.21611/qirt.1994.016

The cylinder was divided into " $n$ " control volumes see fig. 4. and for each of them eq. (3) was written for the point $P$. All this equations represent a system of algebraic equations which can be solved by modified TDMA algorithm known as ADI (Altemating Direction Implicit). The solution of the system gives the temperatures in points $P_{1} \ldots P_{n}$ as a function of the surface temperature versus time.

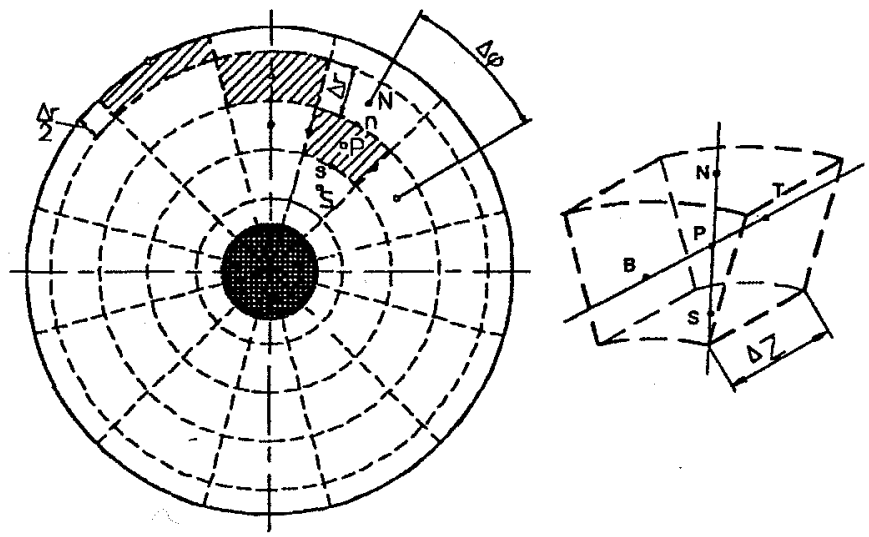

Fig. 3. - Control volumes

\section{Results}

The temperature distribution on the cylinder surface (at $150 \mathrm{sec}$.) decoded from thermograms is shown in fig. 4. The surface thermocouple was the reference for the thermograms reading. The temperatures calculated by means of the two dimensional mathematical model, for one air stream velocity $(1 \mathrm{~m} / \mathrm{s})$, using IR measurement as the input data are shown in fig.

\section{Conclusion}

The comparison of the measured and calculated values shows a good mutual agreement. The main problem is the lack of real values for the heat conduction coefficient, and the heat capacity of the probe material.

It can be concluded that thermography can be easily used for such a measurement and that it in such a case much more comfortable. The results presented give the bases for the future investigations specially directed to the determination of heat transfer coefficients and heat flux for various cooling and heating processes.

\section{REFERENCES}

[1] PATANKAR (S.V.). - Numerical Heat Transfer and Fluid Flow. Hemisphere Publishing Co., Mc Graw-Hill Book Co.

[2] ANDERSON (D.A.), TANNEHILL (J.C.) and PLETCHER (R.H.).- Computational Fluid Mechanics and Heat Transfer. Hemisphere Publishing Co., Mc Graw-Hill Book Co.

[3] LISCIC (B.), SVAIC (S.) and FILETIN (T.).- Workshop Designed System for Quenching Intensity Evaluation and Calculation of Heat Transfer Data. Proceedings of the $1^{\text {st }}$ Intemational Conference on Quenching and Control of Distortion, September .1992, Chicago, Illinois, USA.

[4] SVAIC (S.).- IR Thermography and the Numerical Heat Transfer Analyses. Proceedings of the QIRT 92 Conference, 1992, Paris, France.

[5] SVAIC (S.), SUNDOV (l:) and BABIC (K.).-- Simulation of Cooling the Cylinder in the Surrounding of Artitrary Chosen Temperature. Proceedings of the $37^{\text {th }}$ Intemational Conference KOREMA, 1992, Zagreb, Croatia. 
http://dx.doi.org/10.21611/qirt.1994.016

\section{LOCAL SURFACE TEMPERATURES (150 s)}

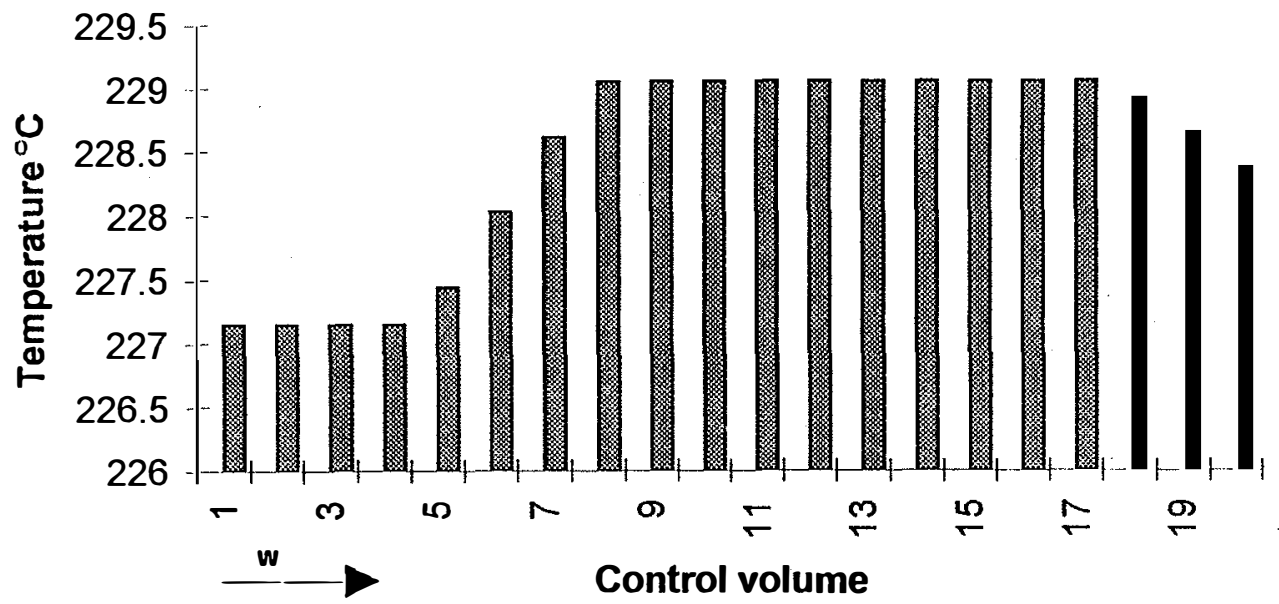

Fig. 4. - The temperature distribution on the cylinder surface
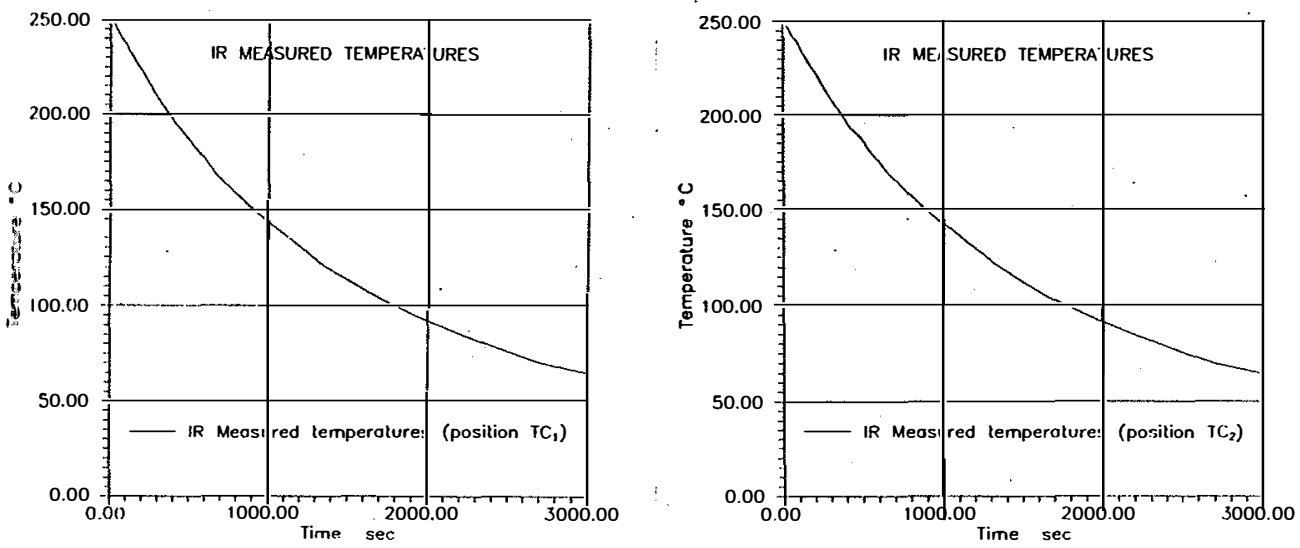
http://dx.doi.org/10.21611/qirt.1994.016
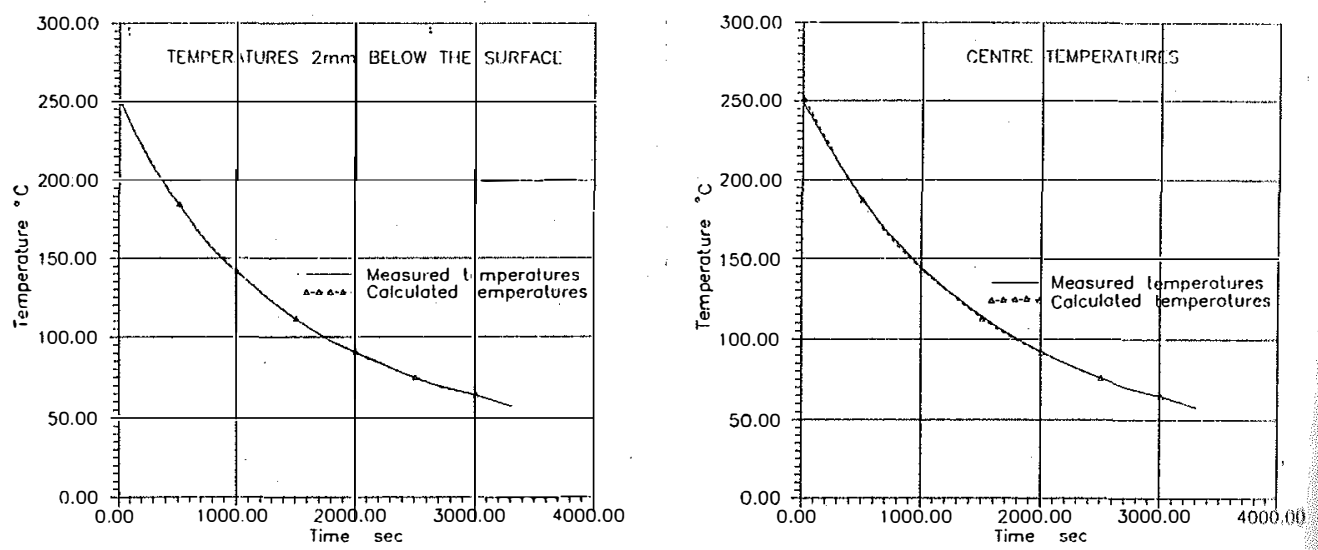

Fig. 5. - Measured and calculated temperatures 